\section{AB025. Acute arthritis with dermatitis: a case of multicentric reticulohistiocytosis}

\section{Omid Zahedi Niaki ${ }^{1}$, Nicole Gunesekera ${ }^{1}$, Christine Lian', Ruth Ann Vleugels ${ }^{1}$, Deborah A. Scott ${ }^{1}$}

${ }^{1}$ Department of Dermatology, Brigham and Women's Hospital, Harvard Medical School, Boston, MA, USA; ${ }^{2}$ Department of Pathology, Brigham and Women's Hospital, Harvard Medical School, Boston, MA, USA

Correspondence to: Ruth Ann Vleugels. Autoimmune Skin Disease Program, Department of Dermatology, Brigham and Women's Hospital, Harvard Medical School, 221 Longwood Avenue, Boston, MA 02115, USA. Email: rvleugels@bwh.harvard.edu.

Abstract: A 56-year-old woman presented with a 5-day history of arthralgias and an erythematous papular eruption affecting the face, arms, chest, and upper back, for which she was started on high potency topical corticosteroids. She was noted to have associated synovitis of the hands and wrists bilaterally and was started on celecoxib. One week later, the patient returned with worsening pain and swelling in her hands in addition to new confluent, somewhat firm, erythematous papulonodules on the face, trunk, forearms, and dorsal hands. Two biopsies were performed with evidence of dermal histiocytic proliferation consistent with multicentric reticulohistiocytosis (MRH). Mycobacterial and malignancy screening were completed, and the patient was started on hydroxychloroquine, methotrexate, and systemic corticosteroids. MRH is a rare histiocytic disorder predominantly affecting Caucasian women in the fourth decade of life. Associations include arthritis, which can be mutilating in nature, and malignancy. Given the frequently destructive nature of the associated arthritis, timely diagnosis and treatment is crucial and may prevent long-term disability. Teaching points: (I) highlight the clinical manifestations of $\mathrm{MRH}$, including the differential diagnosis of arthritis-dermatitis syndromes. (II) Underscore that MRH can mimic dermatomyositis. (III) Describe the differential diagnosis of arthritis mutilans (e.g., RA, PsA, gout, MRH). (IV) Examine the evidence for therapeutic options in MRH.

Keywords: Multicentric reticulohistiocytosis (MRH); coral bead sign; arthritis mutilans

doi: 10.21037/atm.2021.AB025

Open Access Statement: This is an Open Access article distributed in accordance with the Creative Commons Attribution-NonCommercial-NoDerivs 4.0 International License (CC BY-NC-ND 4.0), which permits the noncommercial replication and distribution of the article with the strict proviso that no changes or edits are made and the original work is properly cited (including links to both the formal publication through the relevant DOI and the license). See: https://creativecommons.org/licenses/by-nc-nd/4.0/.

Cite this abstract as: Niaki OZ, Gunesekera N, Lian C, Vleugels RA, Scott DA. Acute arthritis with dermatitis: a case of multicentric reticulohistiocytosis. Ann Transl Med 2021;9(5):AB025. doi: 10.21037/atm.2021.AB025 